\title{
Visual Experience Enhances Infants' Use of Task-Relevant Information in an Action Task
}

\author{
Su-hua Wang and Lisa Kohne \\ University of California, Santa Cruz
}

\begin{abstract}
Four experiments examined whether infants' use of task-relevant information in an action task could be facilitated by visual experience in the laboratory. Twelve- but not 9-month-old infants spontaneously used height information and chose an appropriate (taller) cover in search of a hidden tall toy. After watching examples of covering events in a teaching session, 9-month-old infants succeeded in an action task that involved the same event category; learning was not generalized to events from a different category. The present results demonstrate that learning through visual experience can be transferred to infants' subsequent actions. These findings shed light on the link between perception and action in infancy.
\end{abstract}

Keywords: infancy, perception and action, experience, physical variables, choice tasks

A fundamental aspect of human cognition is to select and use information most relevant to the task at hand. Recent research suggests that infants possess limited ability to keep track of taskrelevant information about object features in dynamic events (e.g., Baillargeon, 2002; Needham, 1998; Wilcox, 1999). For example, infants younger than 12 months of age typically fail to use height information when they watch an event in which a rigid cover is lowered over an object, resulting in their failure to detect a change to the object's height (Wang \& Baillargeon, 2006) and failure to detect a violation when a tall object becomes fully hidden under a short cover (Wang, Baillargeon, \& Paterson, 2005).

Two related accounts help explain the development in infants' ability to use task-relevant information in physical events. First, an event-categorization account suggests that infants attend to information about spatial relations between objects (e.g., whether one object is behind, inside, or under another object) and use it to categorize an event. Recent evidence for this account includes several examples of event categories formed in infancy, such as occlusion, containment, covering, and support events (e.g., Casasola, Cohen, \& Chiarello, 2003; Hespos \& Baillargeon, 2001; McDonough, Choi, \& Mandler, 2003; see Baillargeon \& Wang, 2002, for a review). Second, a variable-identification account suggests that when learning about an event category, infants notice physical variables that mediate the outcomes of events from the category. The age at which infants notice a variable as relevant for

Su-hua Wang and Lisa Kohne, Department of Psychology, University of California, Santa Cruz.

This research was supported by a Junior Scholar Grant from the Chiang Ching-kuo Foundation and by a Special Research Grant from University of California, Santa Cruz to Su-hua Wang. We thank Nameera Akhtar, Maureen Callanan, and Cheryl Gomez for helpful comments; Lili Beggs and Maggie Muir for their help with participant recruitment; and the parents and infants who participated in the research.

Correspondence concerning this article should be addressed to Su-hua Wang, Department of Psychology, University of California, 1156 High Street, Santa Cruz, CA 95064. E-mail: suhua@ucsc.edu an event category depends by and large on the experience infants have with the category (see Baillargeon, 2004, for related discussion). For example, with experience, infants may begin to notice that the height of a cover relative to that of an object determines whether the cover will fully or only partly hide the object when lowered over it (Wang \& Baillargeon, in press). Once a variable is identified, infants routinely use information about the variable for all events they encounter from the category. This account predicts that a variable, once learned, should be generalized across all events from the same category, even when the events involve different stimuli and require different response modalities. The present research tests this prediction, using a laboratory-training approach.

Experience, without a doubt, plays an important role in early development. Past research has shown that motor experience affects the development of distance perception, intentional reaching, and the ability to search for a hidden object (e.g., Campos et al., 2000; Kellman \& Arterberry, 1998; Smith, Thelen, Titzer, \& McLin, 1999; Thelen et al., 1993). More recently, investigators have reported effects of experience at home or in the laboratory on infants' perception and action (e.g., Amso \& Johnson, 2006; Baillargeon, Fisher, \& DeJong, 2000; Needham, 2000; Needham, Barrett, \& Peterman, 2002; Sommerville, Woodward, \& Needham, 2005; Wang \& Baillargeon, 2005, in press; Wilcox \& Chapa, 2004). First, infants' experience acting upon objects enhances their ability to segregate objects (Needham, 2000) and to interpret goal-directed behavior in looking-time tasks (Sommerville et al., 2005); it also elevates infants' level of object exploration (Needham et al., 2002). Second, infants' experience observing an event that highlights an object feature enhances their ability to detect violations involving the same feature when they watch a subsequent event (Wang \& Baillargeon, 2005; Wilcox \& Chapa, 2004). Finally, infants' experience observing exemplars from an event category enhances their ability to detect violations when they watch other events from the same category (Baillargeon et al., 2000; Wang \& Baillargeon, in press). Investigations of experiential effects on infant cognition help specify their underlying mech- 
anisms. Although much evidence for experiential effects in infancy has been obtained, less research is focused on whether the effects are transferred across perception and action modalities. The present research seeks to fill this gap.

The relation between perception and action has been a source of debate (e.g., Bertenthal, 1996; Bremner, 2000; Kellman \& Arterberry, 1998; Willatts, 1997): Investigators have disagreed on whether perception and action operate through the same representational system in early childhood. This debate is derived primarily from the dissociation of young children's performance in looking and search tasks: Whereas looking responses often reveal early success in tracking a hidden object (e.g., Baillargeon, Spelke, \& Wasserman, 1985; Spelke, Breinlinger, Macomber, \& Jacobson, 1992), search responses tend to reveal persistent failure to find a hidden object (e.g., Hood, Carey, \& Prasada, 2000; Mash, Novak, Berthier, \& Keen, 2006) or reveal perseverative errors when an object's hidden location is visibly changed (the A-not-B error; e.g., Diamond, 1985; Munakata, 1997, 1998; Piaget, 1954; Smith et al., 1999). Investigations that sought to explain the looking-search dissociation have focused on frontal cortex maturation and inhibitory control (Diamond, 1991), representation strength (Munakata, 2001), motor history formed during a task (Thelen, Schöner, Scheier, \& Smith, 2001), or differing demands related to looking and search tasks (e.g., Baillargeon, Graber, DeVos, \& Black, 1990; Keen \& Berthier, 2004)

Several approaches have proved helpful to investigating perception-action relations. One such approach compares infants' performance in looking and search tasks that test the same physical intuition; converging evidence across these tasks implies that the same representational system underlies perception and action (e.g., Hespos \& Baillargeon, 2006). Another approach examines whether learning through one modality can be transferred to the other modality. Indeed, there already exists evidence for actionperception transfer. For example, infants' locomotor experience facilitates perception of spatial information (Campos et al., 2000), and their manual experience enhances perception of others' behavior (Sommerville et al., 2005). The present research focuses on perception-action transfer and investigates the issue of perception-action relations by (a) comparing infants' performance in a new action task with that in previous looking-time experiments and (2) testing whether infants transfer what they learn through visual experience to their subsequent performance in the action task.

In Experiment 1, we examined 12-month-old infants' spontaneous use of height information in covering events with a choice task and tested whether this action task would yield converging evidence with previous looking-time reports (Wang \& Baillargeon, 2006; Wang et al., 2005). Experiments 2 and 3 investigated perception-action transfer. We tested 9-month-old infants' performance in the same task and examined whether they could be "taught" through watching examples of covering events to use height information in the task that involved the same event category. In Experiment 4, we asked whether infants would generalize this learning to a different event category.

\section{Experiment 1}

A choice task was designed to assess whether infants attend to and use height information in covering events. A tall toy was hidden, and infants were forced to choose one of two covers in search of the hidden toy. One cover was tall enough to fully hide the toy, and the other was too short. Infants' choice of the tall cover was taken to indicate that they attended to and used height information in this task. Several characteristics of our task made it simple for infants. First, the spatial elements present in the task required minimal integration; stimuli were placed side by side and plainly visible to infants. Second, infants were given two perceptually distinct choices; the two covers were markedly different in height. Third, infants' success required only the use of height information, rather than making a precise prediction of an outcome.

Twelve-month-old infants were tested in Experiment 1. Recent research indicates that infants' action performance often matches their looking responses when the demands of action tasks are low (e.g., Ahmed \& Ruffman, 1998; Berthier et al., 2001; Hespos \& Baillargeon, 2006). Previous looking-time experiments show that infants begin to use height information in covering events at about 12 months (Wang \& Baillargeon, 2006; Wang et al., 2005); thus, we predicted that the 12-month-olds should succeed in the choice task. Additional 12-month-olds were tested in a control condition to assess whether they possess an intrinsic bias for tall over short covers. In this condition, a short toy that could be fully hidden under either cover was used to replace the tall toy.

\section{Method}

Participants. Participants were 32 healthy full-term infants, 15 boys and 17 girls, ranging in age from 11 months 24 days to 13 months 18 days; they were primarily Caucasian from middle-class backgrounds. Half of the infants were randomly assigned to the tall-toy condition (mean age $=12$ months 15 days), and half were randomly assigned to the short-toy condition (mean age $=12$ months 16 days). Four additional infants were tested but excluded from the analyses for not producing any responses (2), for choosing both covers (1), or for parental interference (1). Participants were recruited from birth announcements and local hospitals. Parents received travel reimbursement but were not otherwise compensated for participation.

Apparatus. A table was used with markings (two lines of squares; see Figure 1a) on its surface. The markings served as a visual guide to ensure that stimuli were equidistant from the infants when their choice was made (see Procedure). In the tall-toy condition, a toy bottle and two cylindrical covers were used (see Figure 1b). The toy was $3.3 \mathrm{~cm}$ in diameter, $10.8 \mathrm{~cm}$ high, and filled with yellow liquid. The covers were $5.5 \mathrm{~cm}$ in diameter and decorated with blue contact paper; one was $11.5 \mathrm{~cm}$ high and the other $4.5 \mathrm{~cm}$ high. In the short-toy condition, the same covers were used along with a toy rhinoceros $(4 \mathrm{~cm}$ high). A rectangular screen was used in both conditions for hiding the stimuli during the task (see below); it was $40 \mathrm{~cm}$ wide, $32 \mathrm{~cm}$ high, and decorated with pastel contact paper.

Procedure. During the experiment, the infant sat on the parent's lap in a cut-out area against the front edge of the table; an experimenter sat across from the infant. The parent was instructed to remain silent and neutral. Each infant received a single trial consisting of a showing and a test phase; the order and location of the cover in use were counterbalanced across infants. 


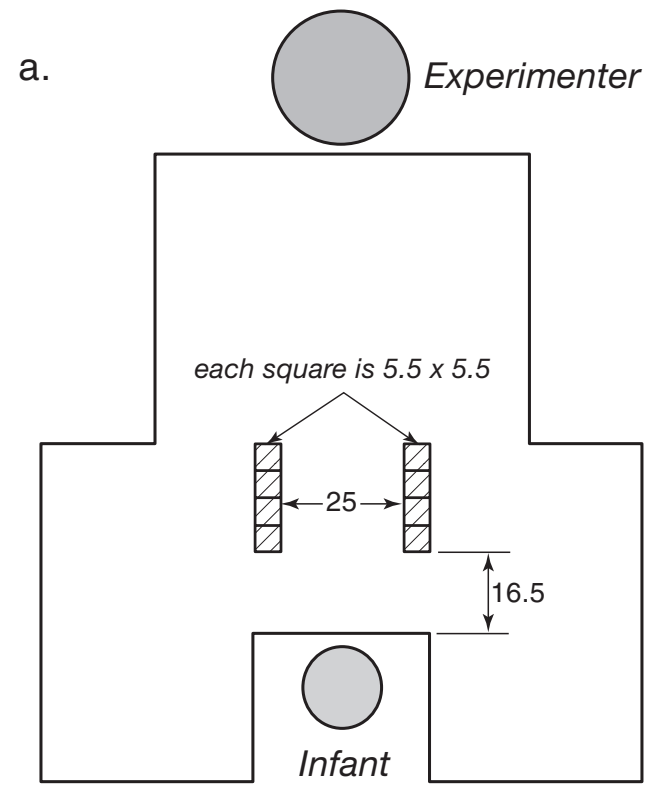

b.
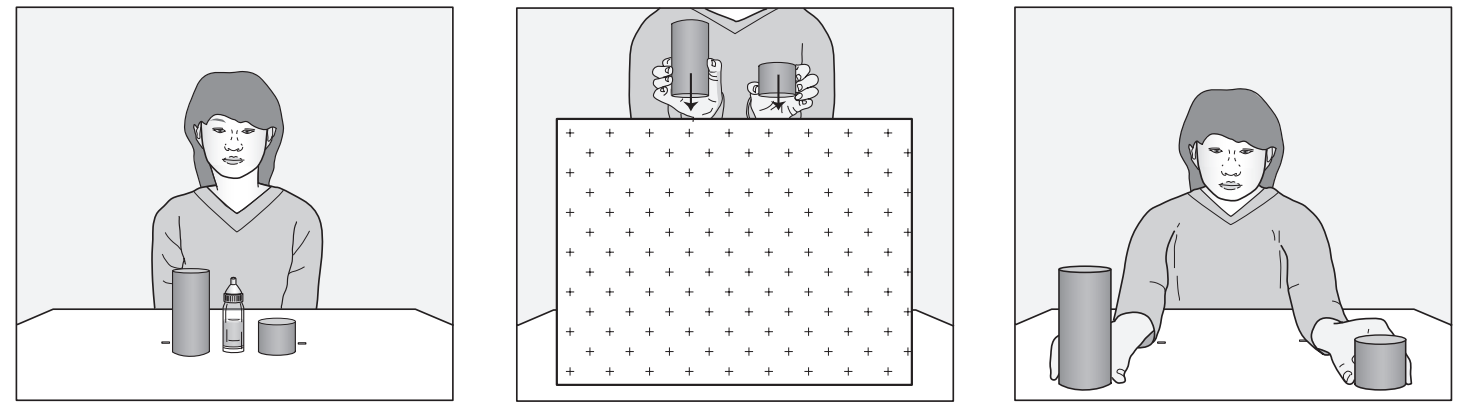

Figure 1. Schematic drawings of a bird's eye view of the table (a) and the test phase of the choice task (b). Numbers represent the dimensions in centimeters.

At the beginning of the showing phase, the screen was placed on the table, $38 \mathrm{~cm}$ from the infant; the covers and toy stood behind the screen so that attention could easily be directed to whichever object was being shown. To start, the experimenter retrieved a cover from behind the screen, tapped the side of the cover, showed its closed top and hollow interior, and then gave it to the infant. After $10 \mathrm{~s}$ (determined by a timer), the experimenter retrieved the cover from the infant and placed it behind the screen, and then repeated the same showing sequence with the other cover. Next, the infant was given the toy for $15 \mathrm{~s}$. The experimenter then removed the screen and set it on the floor, revealing the two covers that stood $6.5 \mathrm{~cm}$ apart and $53.5 \mathrm{~cm}$ from the infant. Finally, the toy was placed in the center between the two covers.

At the start of the test phase, the experimenter tapped the top of the toy to draw the infant's attention, lowered one cover to hide the top centimeter of the toy, and then repeated this sequence with the other cover. Next, the screen was placed at its starting position on the table, fully hiding all stimuli. The covers were lifted above and then lowered behind the screen. After the toy was hidden, the experimenter placed the screen on the floor and slid the two covers simultaneously toward the infant, using the markings on the table to ensure that the covers were equidistant from the infant. ${ }^{1}$ The experimenter then released the covers and looked at the timer on the wall behind the infant. If no response was produced within $30 \mathrm{~s}$, the experimenter slid both covers $5.5 \mathrm{~cm}$ closer to the infant and waited for another $30 \mathrm{~s}$. The trial ended after the second attempt; participants who failed to produce any responses were replaced.

The infants' responses during the 30-s interval (starting from the experimenter's releasing the covers) were coded frame by frame by two independent coders. The coders did not see the height of the

\footnotetext{
${ }^{1}$ The covers were placed outside the infant's immediate reach to encourage or force the infant to choose only one cover. Thus, the distance between the covers and infant varied across participants, depending on the infant's arm length. The experimenter determined the distance while the infant was seated with her or his hands placed on the table near the markings. In this and the following experiments, the cover-infant distance ranged from 16.5 to $33 \mathrm{~cm}$.
} 
hidden toy and were blind to the research hypothesis, the infant's age, and the condition assigned to the infant. The coders determined which cover was first reached and contacted by the infant's finger or palm; infants who contacted both covers within a 2-s interval were replaced. A reliability check on whether the coders agreed on the choice of cover was conducted for each infant; intercoder agreement in this and the following experiments was $100 \%$.

To assess whether the infants used auditory cues to make their choice, we separately recruited 16 college students. These students received the same task while being blindfolded (so that they could only rely on auditory cues to determine the location of the hidden toy). Only 9 of them answered correctly about whether the toy was on their left or right at the end of the task, $\chi^{2}(1, N=16)=1.44$, $p>.10$, ruling out auditory cues as a confounding variable.

\section{Results and Discussion}

As shown in Figure 2, thirteen infants in the tall-toy condition chose the tall cover, $\chi^{2}(1, N=16)=6.13, p<.025$, whereas only 7 infants in the short-toy condition did so, $\chi^{2}(1, N=16)=0.25$; the difference between these two conditions was reliable, $\chi^{2}(1, N=32)=4.80, p<.05$. These results suggest that the 12-month-old infants attended to height information, recognized that the tall toy could be fully hidden under the tall but not the short cover, and thus systematically chose the tall cover in search of the hidden toy. The short-toy control condition provided support for this interpretation, showing that the infants' success in the tall-toy condition did not reflect a bias for the tall cover; when the hidden toy was shorter than either cover, the infants made a random choice. Together, these findings are consistent with previous looking-time reports that infants at 12 months attend to and use height information in covering events (Wang \& Baillargeon, 2006; Wang et al., 2005).

\section{Experiment 2}

The purpose of Experiment 2 was twofold: (a) using the choice task to test whether 9-month-old infants would fail, as indicated by previous looking-time reports, to consider height information in covering events, and (b) beginning to examine whether infants could be taught to do so, through watching others demonstrate the relevance of the variable height in a series of covering events. Nine-month-old infants completed a three-phase procedure consisting of a preteaching choice task, a teaching session, and a postteaching choice task.

\section{Method}

Participants. Sixteen 9-month-old infants participated (9 boys and 7 girls; mean age $=9$ months 11 days; range $=8$ months 25 days to 10 months 2 days). Two additional infants were tested but eliminated for not producing any responses during the preteaching task. In this and the following experiments, the participants were recruited in the same way and demographically similar to those in Experiment 1 .

Apparatus. The pre- and postteaching tasks were conducted as in Experiment 1 with one exception: a toy giraffe $(10.5 \mathrm{~cm}$ high) replaced the toy bottle in the postteaching task. Like the bottle, the giraffe could be fully hidden under the tall but not the short cover.

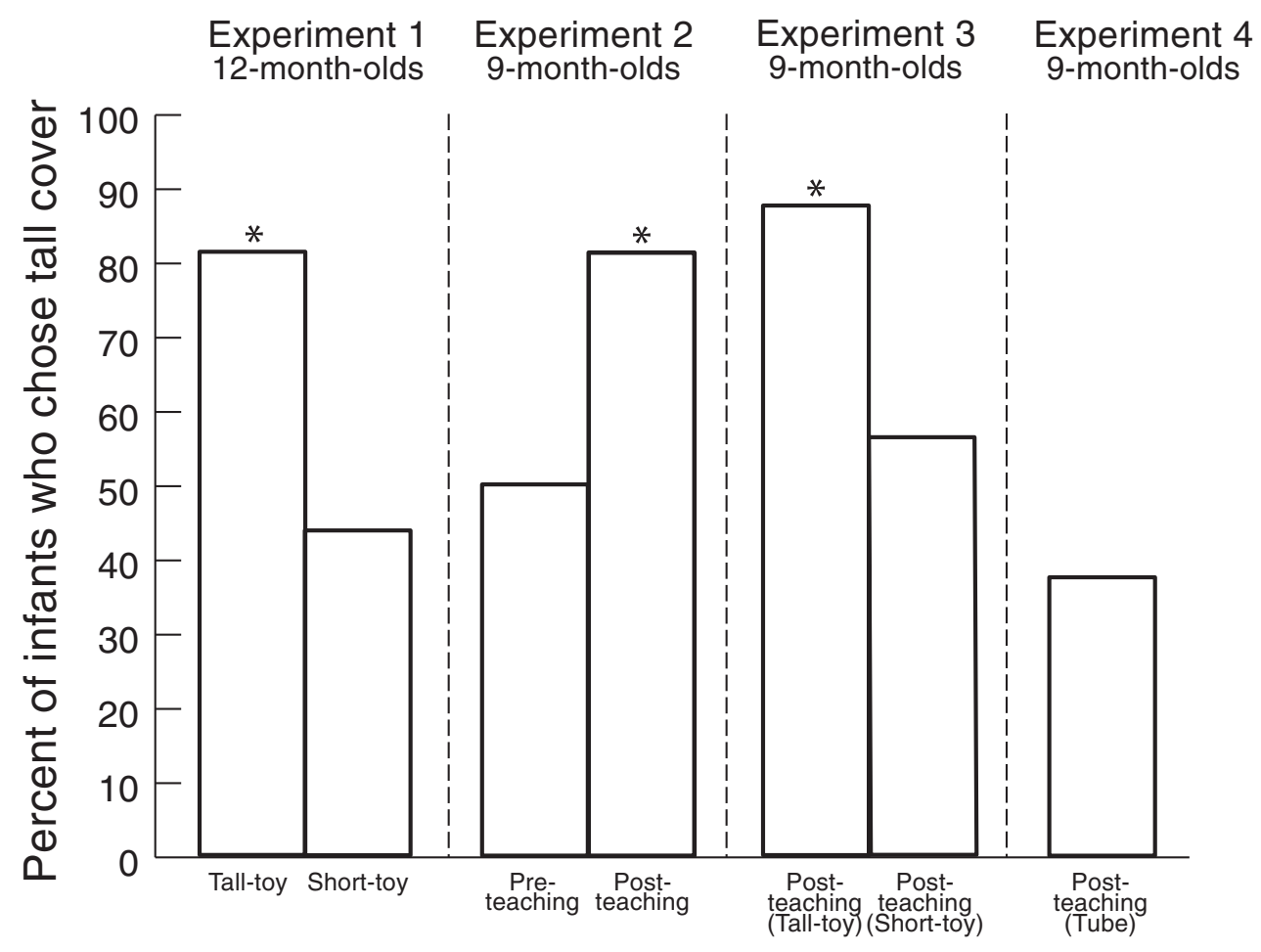

Figure 2. Percentage of the infants who chose the tall cover in each experiment. ${ }^{*} p<.05$. 
During the teaching session, a display booth located in a different room was used for presenting covering events; this booth was designed following previous experiments (Wang \& Baillargeon, in press). The stimuli for the teaching session included a cylindrical object and three pairs of covers. The object was $14.7 \mathrm{~cm}$ high, 5.5 $\mathrm{cm}$ in diameter, and decorated with dotted contact paper. Each pair of covers (10.5 cm in diameter) consisted of a tall and a short cover; across pairs, the covers varied in height, color, and pattern (see Figure 3a).

Procedure. Each infant received a preteaching choice task, six teaching trials, and a postteaching choice task; they were administered consecutively on the same day. The preteaching task was conducted as in the tall-toy condition of Experiment 1. Upon completion, the infants were brought to another room for the teaching session conducted by a different experimenter. During this session, the infants watched three pairs of covering events; each pair included a fully and a partly hidden event (see Figure $3 b$ ). Half of the infants saw the fully hidden event first, and half saw the partly hidden event first. In the fully hidden events, the tall cover stood centered to the left of the object. The experimenter's right hand (in a yellow glove) rotated the cover upward to show its hollow interior. When the infant had looked at this scene for 2 cumulative seconds, the cover was returned to its starting position. After the infant had looked at this display for 2 cumulative seconds, the event proper began. The cover was lifted

a.

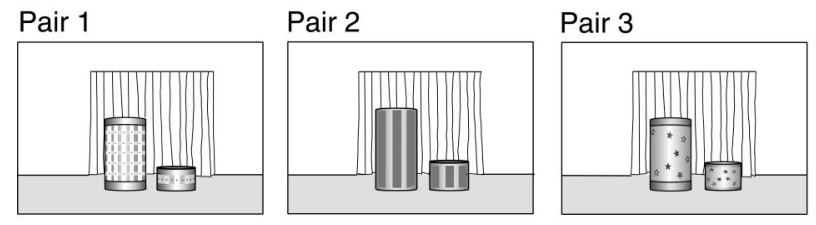

b.

Fully hidden event
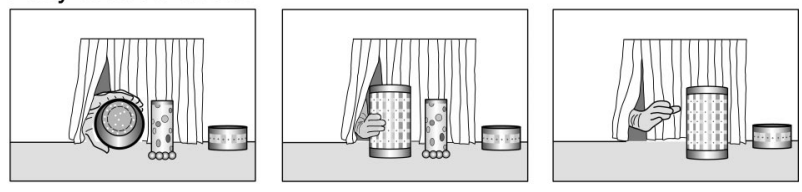

Partly hidden event
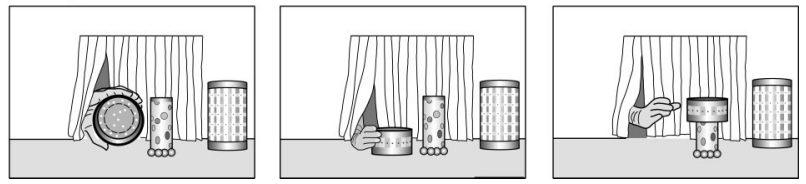

Figure 3. Schematic drawings of the covers used during the first, second, and third pair of teaching trials in Experiments 2 to 4 (a) and the first pair of teaching events (b). The first pair of covers $(17.5 \mathrm{~cm}$ and $6 \mathrm{~cm}$ high) was green with a checkered pattern; the second pair $(20 \mathrm{~cm}$ and $11 \mathrm{~cm}$ high) was yellow with vertical stripes; the third pair $(15 \mathrm{~cm}$ and $7.5 \mathrm{~cm}$ high) was ivory with star-shaped stickers. The chosen heights enabled the tall cover from each pair to completely hide the object and the short cover to only partially hide the object.
( $2 \mathrm{~s})$, moved to the right above the object (1 s), lowered over it ( $2 \mathrm{~s})$, and then released (1 s). After a 1-s pause, the hand grasped the cover ( $1 \mathrm{~s})$, lifted ( $2 \mathrm{~s}$ ) and moved it to the left of the object (1 $\mathrm{s})$, lowered it to its starting position ( $2 \mathrm{~s})$, and then paused for $1 \mathrm{~s}$. Each event cycle lasted about $14 \mathrm{~s}$; cycles were repeated until the trial ended. The partly hidden events were conducted similarly with the short covers.

Each teaching trial ended when the infant either (a) looked away from the event for 2 consecutive seconds after having looked at it for at least 14 cumulative seconds or (b) looked for 60 cumulative seconds without looking away for 2 consecutive seconds. The 14-s minimum value ensured that the infant had the opportunity to observe at least one cycle of the event. Two observers monitored the infants' looking behavior through peepholes in large clothcovered frames on either side of the display booth. The primary (and usually more experienced) observer's looking times determined when a trial ended. Interobserver agreement during the teaching trials in this and the following experiments averaged $95 \%$ per trial per infant.

After the teaching session, the infants returned to the first room for the postteaching task, which was the same as the preteaching task except for the toy used. In this and the following experiments, the time elapsed during infants' traveling between the two experimental rooms averaged 2 min 56 s per infant.

Preliminary analyses of the infants' looking times during the teaching trials in this and the following experiments revealed no significant interactions (all $F \mathrm{~s}<1.00$ ) involving event (fully or partly hidden) and gender, pair (the first, second, or third pair of teaching trials), or order (fully hidden event presented first or second). The data were therefore collapsed across gender, pair, and order in subsequent analyses.

\section{Results and Discussion}

Preteaching choice task. The 9-month-olds responded at chance levels (see Figure 2): 8 of them chose the tall cover, $\chi^{2}(1$, $N=16)=0.00$, suggesting that they did not consider height information in search of the hidden tall toy. This result is consistent with previous looking-time findings that infants under 12 months typically fail to use height information when watching covering events (Wang \& Baillargeon, 2006; Wang et al., 2005). ${ }^{2}$

Teaching session. The infants' looking times during the teaching trials were averaged across pairs and analyzed by a one-way analysis of variance (ANOVA), with event (fully or partly hidden) as a within-subject factor. The main effect of event was not significant, $F(1,15)=0.02$, suggesting that the infants looked about equally at the fully $(M=33.9 \mathrm{~s})$ and partly $(M=33.6 \mathrm{~s})$ hidden events.

Postteaching choice task. After watching the teaching events, 13 infants chose the tall cover, $\chi^{2}(1, N=16)=6.13, p<.025$.

\footnotetext{
${ }^{2}$ During the choice task, the screen was placed in front of all stimuli. Did the infants categorize the task as an occlusion rather than a covering event? Previous research indicates that infants from 3.5 months consider height information in occlusion events (Baillargeon \& DeVos, 1991; Hespos \& Baillargeon, 2001). Had the infants categorized the task as an occlusion event, they should have succeeded at 9 months without teaching.
} 
Inspection of each participant's pre- and postteaching responses indicated that 6 out of the 8 infants who initially chose the short cover changed their choice in the postteaching test, whereas only 1 out of the 8 infants who initially chose the tall cover did so. A one-tailed McNemar test confirmed that the teaching session yielded a higher change ratio in the infants who failed than in those who succeeded in the preteaching test, $\chi^{2}(1, N=16)=3.57$, $p<.05$.

Together, these results suggest that after watching the covering events in the teaching session, the 9-month-olds began to use height information and realized that the tall toy could be fully hidden under the tall but not the short cover. The variable height, identified through brief visual experience (about $200 \mathrm{~s}$ ), guided the infants to succeed in the choice task several months earlier than they would without teaching. Thus, the infants in Experiment 2 gave initial evidence that they generalized a newly identified variable across events from the same category and transferred their visual learning to subsequent actions. Such transfer occurred even when the teaching and test contexts were markedly different; recall that different rooms, apparatuses, and experimenters were used and that the teaching stimuli were much larger than and perceptually distinct from the test stimuli.

However, the results in Experiment 2 are subject to two alternative interpretations. First, given the within-subject design, one could argue that the infants' success in the postteaching test was derived not from their experience in the teaching session but from their exposure to the preteaching test (a practice effect). Perhaps completing one choice task had cued infants to use height information in the next choice task. Second, although the 9-month-olds did not exhibit a superficial bias for tall covers in the preteaching test, they might have developed such a bias during the teaching session. Perhaps some aspects of the teaching events had made tall covers more appealing than short covers, guiding infants to choose the tall cover in the postteaching test (a superficial bias). We addressed these issues in the following experiment.

\section{Experiment 3}

To examine the practice-effect interpretation, we tested one group of 9-month-olds in a tall-toy condition with a two-phase procedure consisting of a teaching session and a postteaching choice task; no preteaching choice task was given to these infants. According to this interpretation, the infants should fail in the postteaching task after the removal of preteaching practice. To examine the superficial-bias interpretation, we tested another group of 9-month-olds in a short-toy condition with a similar two-phase procedure, except that we used a short toy that could be fully hidden under either cover. If the teaching events induced in the infants a superficial bias for tall covers, the infants in this condition should still find the tall cover intrinsically appealing and choose it in the postteaching task. Conversely, our interpretation of the results in Experiment 2 predicted an opposite response pattern: The infants in the tall-toy condition should succeed in the postteaching task, whereas those in the short-toy condition should not.

\section{Method}

Participants. Thirty-two 9-month-old infants (18 boys and 14 girls; range $=8$ months 20 days to 10 months 4 days) were randomly assigned to the tall-toy (mean age $=9$ months 18 days) or short-toy (mean age $=9$ months 7 days) conditions. Two additional infants were tested but eliminated, 1 for choosing both covers and 1 for fussiness.

Apparatus and procedure. The apparatus and procedure were identical to those in Experiment 2, except that the infants did not receive the preteaching task. The postteaching task was conducted as in the tall- or the short-toy condition of Experiment 1.

\section{Results and Discussion}

Teaching session. The infants' looking times at the teaching events were compared by a $2 \times 2$ ANOVA, with condition (tall or short toy) as a between-subjects factor and event (fully or partly hidden) as a within-subject factor. No effect was significant, $F \mathrm{~s}(1$, $30)<2.95, p s>.09$, indicating that the infants in both conditions looked about equally at the fully and partly hidden events $(M=$ $33.1 \mathrm{~s}$ and $30.1 \mathrm{~s}$, respectively).

Postteaching choice task. The infants in the tall-toy condition systematically chose the tall cover $(14 / 16), \chi^{2}(1, N=16)=9.00$, $p<.005$, whereas those in the short-toy condition performed at chance levels $(9 / 16), \chi^{2}(1, N=16)=0.25$; the difference between these two conditions was reliable, $\chi^{2}(1, N=32)=3.86, p<.05$. Given no preteaching task, the infants in the tall-toy condition still succeeded in the postteaching task, suggesting that the positive results in Experiment 2 were not due to a practice effect. In addition, when the toy was shorter than either cover, the infants' choice of the tall cover was at chance, ruling out the superficialbias interpretation. Together, these results provided further evidence for our interpretation that observing covering events enhanced 9-month-olds' ability to use height information in the choice task.

We have argued so far that the teaching events used in Experiments 2 and 3 helped the 9-month-olds notice height as a relevant variable for covering events and thereby guided them to use height information in the task involving the same event category. Could these results be explained by a different account? Recent reports suggest that infants who have not yet identified a variable as relevant can be induced, through various contextual manipulations, to attend to information about this variable (e.g., Wang \& Baillargeon, 2005); one such report appealed to a perceptual-salience account (Wilcox \& Chapa, 2004). When watching occlusion events, infants under 11.5 months typically fail to attend to color information (Wilcox, 1999). To direct infants' attention to color, Wilcox and Chapa (2004) showed 9.5-month-olds pretest events that highlighted green and red colors by using a green and a red cup to perform different actions. With this exposure, the infants succeeded in detecting a violation involving green and red colors in occlusion events. The results were taken to suggest that (a) the infants perceived the association between the color and function of the cups demonstrated in the pretest events and that (b) this association made green and red colors perceptually salient, guiding the infants to attend to these colors. Subsequent experiments (Wilcox \& Wood, in press) showed that the infants succeeded only when the colors used in the pretest events were the same as those in the test events. This manipulation thus served to highlight a physical variable and, more precisely, particular values (i.e., the green and red colors) of a variable. 
Previous research indicates that infants treat events involving covers (with one open end at the bottom) and tubes (with two open ends) as distinct categories: Although they begin to use height information in covering events at 12 months, they fail to do so in tube events until about 14 months (Wang \& Baillargeon, 2006; Wang et al., 2005). This finding provides an opportunity for us to examine whether our effects are derived from increasing the perceptual salience of target information as in Wilcox and Chapa's (2004) study or from teaching infants the relevance of a variable for an event category as we have proposed. In Experiment 4, 9-month-olds were tested as in Experiment 3, except that the closed tops of the covers used in the choice task were removed to form tubes. If the perceptual-salience mechanism underlies our results, the infants may still attend to and use height information in the postteaching task when the geometry of test stimuli is slightly modified. ${ }^{3}$ In contrast, if the mechanism involves identifying a variable for a specific event category (covering events), infants should fail to apply the variable to a different category (tube events).

\section{Experiment 4}

\section{Method}

Participants. Sixteen infants ( 7 boys and 9 girls; mean age $=$ 9 months 8 days; range $=8$ months 21 days to 10 months 0 day) participated in this experiment.

Apparatus and procedure. The infants received six teaching trials and a postteaching choice task. The apparatus and procedure were similar to those in the tall-toy condition of Experiment 3, except that the closed tops of the covers in the choice task were removed to form tubes. During the task, the tubes were used in the same manner as the covers in Experiment 3.

\section{Results and Discussion}

Teaching session. The infants' looking times at the teaching events were analyzed by an ANOVA, with event (fully or partly hidden) as a within-subject factor. No effect was significant, $F(1$, $15)=0.00$, indicating that the infants looked equally at the fully and partly hidden events ( $M=33.1 \mathrm{~s}$ for both events).

Postteaching choice task. After watching the teaching events, the infants responded at chance $\left(6 / 16\right.$ chose the tall tube), $\chi^{2}(1$, $N=16)=1.00$. The results in this experiment and in the tall-toy condition of Experiment 3 were reliably different, $\chi^{2}(1, N=32)=$ $8.53, p<.005$, even though the infants in the two experiments had received identical teaching trials.

These results are consistent with previous looking-time findings that infants under 14 months typically fail to use height information in events involving tubes (Wang \& Baillargeon, 2006; Wang et al., 2005). More important, they helped rule out the perceptualsalience interpretation. Recall that the postteaching task in this experiment was identical to that in Experiment 3 except for the removal of the covers' closed tops. If the teaching events merely highlighted height information in general, they should have helped the infants attend to and use this information whether covers or tubes were used in the task. The results suggest that the infants may have treated tube events as distinct from covering events and failed to apply the variable height when the task crossed the boundary of two event categories. We discuss this issue further in the General Discussion.

\section{General Discussion}

The present research sought to investigate two issues: (a) the effect of visual experience on infants' use of task-relevant information in an action task and (b) the link between perception and action in infancy. Four experiments examined infants' use of height information in a choice task involving covers. Twelvemonth-old infants spontaneously used height information and chose the correct (taller) cover in search of a hidden tall toy, whereas 9-month-old infants failed to do so. With a brief visual exposure to covering events, 9-month-olds learned to use height information and succeeded in the choice task involving covers but not tubes. This experiential effect was obtained when the teaching and test contexts were markedly different and regardless of whether the infants had received the task prior to the visual exposure. Thus, the results provide strong evidence that 9-monthold infants learn to use task-relevant information through visual experience and apply this learning in events from the same category in an action task. Our results provide evidence for perception-action transfer; they also match previous looking-time findings on 9- and 12-month-olds' spontaneous use of height information in covering events (Wang \& Baillargeon, 2006; Wang et al., 2005).

In the following sections, we discuss the implications and underlying mechanisms of our findings in relation to the existing literature, point out limitations of the present research, and suggest possible investigations for future research.

\section{Perception-Action Relation}

A number of looking-time experiments have shown that young infants are fairly skilled at applying a basic physical principle, solidity, a notion that one object cannot pass through another object (e.g., Spelke, 1994; Spelke et al., 1992; Wang et al., 2005). For example, 2.5-month-olds responded with prolonged looking time to an event in which a ball appeared to pass through a barrier, suggesting that they considered the solidity principle and were intrigued by the event violating this principle (Spelke et al., 1992). In sharp contrast, several experiments have shown that 2-year-old toddlers are fairly poor at applying the same principle in search of a hidden object (see Keen, 2003, for a review). In one experiment (Berthier et al., 2000), 2-year-olds watched an event in which a ball rolled down a ramp behind an occluder and a barrier stood on the ramp blocking its trajectory. Four identical doors were embedded in the occluder, one of which aligned with the barrier and hence stood right in front of the stopped ball. The 2-year-olds failed to choose the correct door in search of the hidden ball. Similar failures have been observed with variations in the barrier orientation, the event sequence, or the number of choices given to the toddlers (e.g., Hood et al., 2000; Mash et al., 2006). The discrepancy in children's looking and search responses led to a

\footnotetext{
${ }^{3}$ The perceptual-salience effects were obtained by Wilcox and Chapa (2004) even when the pretest and test events involved different spatial relations and different stimuli.
} 
proposal that perception and action operate through separate representational systems.

The present research obtained different results from the above literature. Consistent with the looking-time reports (Wang \& Baillargeon, 2006; Wang et al., 2005), the 12-month-olds succeeded and the 9-month-olds failed to use height information in the events involving covers. No discrepancy was found in infants' looking and action responses. Furthermore, the 9-month-olds in Experiments 2 and 3 transferred what they learned through visual experience to their subsequent actions, providing support for the link between perception and action.

What contributes to the consistency of infants' performance in our action and previous looking-time tasks, and what accounts for the 12-month-olds' outperforming the 2-year-olds in seemingly similar choice tasks? As noted earlier, our choice task incorporated several features that made it simple for infants. First, it included a minimal amount of spatial information to be integrated; for example, aside from the toy, no additional objects (e.g., a barrier) were present that needed to be aligned with the covers. Second, it did not require infants to predict the proportion of the toy to be hidden under the covers, whereas the toddlers in previous research (e.g., Berthier et al., 2000) had to judge the amount of the distance traveled by the ball to infer its current location. Third, the two choices given to our participants differed markedly in height, whereas the toddlers had to pick from two or more identical choices. We believe that these differences may have contributed to the 12-month-olds' success in Experiment 1 and the converging results of our and previous looking-time experiments. The present findings thus provide support for the proposal that children's success in perception tasks and their failure in action tasks may be a product of differing task demands (Keen, 2003).

\section{Origins of Experiential Effect}

Through brief experience with covering events, the 9-month-old infants in Experiments 2 and 3 learned to use height information and chose the appropriate cover in search of a hidden toy. What mechanism underlies this experiential effect? There are at least two possibilities. One involves a familiarization process: The exposure to covering events in the teaching session might familiarize infants with actions involving lowering a cover over an object and reduce the attentional resources needed for processing such covering actions. Hence, increased resources might become available for infants to use height information in the postteaching task. However, it is unclear how familiarity with covering actions alone could enhance infants' processing of the postteaching task, given that the actual hiding sequence occurred behind the screen and was not visible to infants.

Another mechanism, which we have alluded to throughout this article, involves a process by which infants identify the relevance of a physical variable for an event category. An explanation-based learning account (e.g., Baillargeon, 2004; Wang et al., 2005) proposed that three components may be essential for the experiential effect to be obtained. First, infants must notice contrastive outcomes of events involving the same or similar objects. In the present case, the teaching object sometimes became fully and sometimes became partly hidden under a cover. Noticing this contrast may serve to trigger infants' search for determinants of the event's outcome. Second, infants need to gather information about the variable and map it onto the differing outcomes. In the present case, the teaching cover was placed on the floor next to the object multiple times, making it easy for the infants to judge whether the cover was taller or shorter than the object. This condition information could then be linked to the contrastive outcomes infants observed. Third, recent research indicates that infants are better at detecting causally plausible as opposed to anomalous regularities (Baillargeon, 2002; Newcombe, Sluzenski, \& Huttenlocher, 2005). Thus, causal reasoning may also play an important role: that of integrating infants' existing knowledge and the conditionoutcome association. In the present case, the infants were shown the hollow interior of each cover at the beginning of each teaching trial. This observation allowed them to integrate the solidity principle with the events they observed: A tall object could extend to its full height inside a deep but not a shallow cover. In a recent report, learning effects diminished when each of the above components was removed from teaching events (Wang \& Baillargeon, in press), providing support for this account.

There are some limitations in the present research. We tested whether infants transfer visual learning to subsequent actions; it is unclear whether experience has to be visual for such learning to occur. However, on the basis of the above account, infants should be in a good position to identify a new variable when (a) they are exposed to contrastive outcomes, (b) the condition information is available, and (c) the experience allows them to integrate existing knowledge with new observation, whether by acting upon objects or by observing others do so. Recent findings also provide evidence for action-perception and action-action transfer in infancy (Needham, 2000; Needham et al., 2002; Sommerville et al., 2005). Thus, we suspect that deliberate action experience that supplies the above three components should yield similar effects.

Another limitation relates to the use of tubes in Experiment 4. The negative results were taken to rule out a perceptual-salience interpretation and to support the fact that infants fail to generalize a new variable to tasks involving a different event category. This finding potentially helps deepen researchers' understanding of event categorization in infancy and its relationship with learning. First, it suggests that when categorizing an event, infants consider not only the spatial relation between objects but also the geometry of the stimuli involved (e.g., whether an object has one or two open ends). Second, it implies that infants' learning processes allow broad, yet circumscribed, generalization: A variable identified in an event category will be attended to in any event from the category-but only in events from the category. However, one could argue that infants failed to use height information because they were distracted by the open ends of the tubes. We speculate that this possibility is unlikely to be true because the infants in Experiment 4 were given the same amount of time as in other experiments to acquaint themselves with the tubes. Future research can examine this issue by testing whether positive effects will be obtained when infants are given more time to inspect the tubes. One could also test infants' performance in the choice task after they watch teaching events conducted with tubes; findings that infants still fail in the choice task will support the distraction interpretation.

To conclude, consistent with previous looking-time reports, the present research indicates that 12-month-old infants spontaneously succeeded and 9-month-old infants failed to use height information in an action task involving covering events. This finding provides 
support for the proposal that infants' action performance parallels their looking responses when task requirements are simple. Furthermore, the present research provides strong evidence for experiential effects on infants' use of task-relevant information. Infants at 9 months learn to use height information after watching others demonstrate the relevance of this information in a brief teaching session. Although future research is still needed to specify the mechanism underlying this experiential effect, the present research makes it clear that infants' use of task-relevant information in an action task can be enhanced through brief visual experience.

\section{References}

Ahmed, A., \& Ruffman, T. (1998). Why do infants make A not B errors in search task, yet show memory for the location of hidden objects in a nonsearch task? Developmental Psychology, 34, 441-453.

Amso, D., \& Johnson, S. P. (2006). Learning by selection: Visual search and object perception in young infants. Developmental Psychology, 42, $1236-1245$

Baillargeon, R. (2002). The acquisition of physical knowledge in infancy: A summary in eight lessons. In U. Goswami (Ed.), Handbook of childhood cognitive development (pp. 47-83). Oxford, England: Blackwell.

Baillargeon, R. (2004). Infants' reasoning about hidden objects: Evidence for event-general and event-specific expectations. Developmental Science, 7, 391-424.

Baillargeon, R., \& DeVos, J. (1991). Object permanence in young infants: Further evidence. Child Development, 62, 1227-1246.

Baillargeon, R., Fisher, C., \& DeJong, G. F. (2000, July). Teaching infants about support: What data must they see? Paper presented at the Biennial International Conference on Infant Studies, Brighton, England.

Baillargeon, R., Graber, M., DeVos, J., \& Black, J. (1990). Why do young infants fail to search for hidden objects? Cognition, 36, 255-284.

Baillargeon, R., Spelke, E. S., \& Wasserman, S. (1985). Object permanence in 5-month-old infants. Cognition, 20, 191-208.

Baillargeon, R., \& Wang, S. (2002). Event categorization in infancy. Trends in Cognitive Sciences, 6, 85-93.

Bertenthal, B. I. (1996). Origins and early development of perception, action, and representation. Annual Review of Psychology, 47, 431-459.

Berthier, N. E., Bertenthal, B. I., Seaks, J. D., Sylvia, M. R., Johnson, R. L., \& Clifton, R. K. (2001). Using object knowledge in visual tracking and reaching. Infancy, 2, 257-284.

Berthier, N. E., DeBlois, S., Poirier, C. R., Novak, M. A., \& Clifton, R. K. (2000). Where's the ball? Two- and three-year-olds reason about unseen events. Developmental Psychology, 36, 394-401.

Bremner, J. G. (2000). Developmental relationships between perception and action in infancy. Infant Behavior \& Development, 23, 567-582.

Campos, J. J., Anderson, D. I., Barbu-Roth, M. A., Hubbard, E. M., Hertenstein, M. J., \& Witherington, D. (2000). Travel broadens the mind. Infancy, 1, 149-219.

Casasola, M., Cohen, L., \& Chiarello, E. (2003). Six-month-old infants' categorization of containment spatial relations. Child Development, 74, 679-693.

Diamond, A. (1985). Development of the ability to use recall to guide action, as indicated by infants' performance on A-not-B. Child Development, 56, 868-883.

Diamond, A. (1991). Neuropsychological insights into the meaning of object concept development. In S. Carey \& R. Gelman (Eds.), The epigenesis of mind: Essays on biology and cognition (pp. 67-110). Hillsdale, NJ: Erlbaum.

Hespos, S. J., \& Baillargeon, R. (2001). Infants' knowledge about occlusion and containment events: A surprising discrepancy. Psychological Science, 12, 140-147.

Hespos, S. J., \& Baillargeon, R. (2006). Décalage in infants' knowledge about occlusion and containment events: Converging evidence from action tasks. Cognition, 99, B31-B41.

Hood, B., Carey, S., \& Prasada, S. (2000). Predicting the outcomes of physical events: Two-year-olds fail to reveal knowledge of solidity and support. Child Development, 71, 1540-1554.

Keen, R. (2003). Representation of objects and events: Why do infants look so smart and toddlers look so dumb? Current Directions in Psychological Science, 12, 79-83.

Keen, R., \& Berthier, N. (2004). Continuities and discontinuities in infants' representation of objects and events. In R. V. Kail (Ed.), Advances in child development and behavior (pp. 243-279). San Diego, CA: Elsevier Academic Press.

Kellman, P. J., \& Arterberry, M. E. (1998). The cradle of knowledge: Development of perception in infancy. Cambridge, MA: MIT Press.

Mash, C., Novak, E., Berthier, N., \& Keen, R. (2006). What do two-yearolds understand about hidden-object events? Developmental Psychology, 42, 263-271.

McDonough, L., Choi, S., \& Mandler, J. M. (2003). Understanding spatial relations: Flexible infants, lexical adults. Cognitive Psychology, 46, $229-259$

Munakata, Y. (1997). Perseverative reaching in infancy: The roles of hidden toys and motor history in the $\mathrm{AB}$ task. Infant Behavior and Development, 20, 405-416.

Munakata, Y. (1998). Infant perseveration and implications for object permanence theories: A PDP model of the A-not-B task. Developmental Science, 1, 161-211.

Munakata, Y. (2001). Graded representations in behavioral dissociations. Trends in Cognitive Sciences, 5, 309-315.

Needham, A. (1998). Infants' use of featural information in the segregation of stationary objects. Infant Behavior and Development, 21, 47-76.

Needham, A. (2000). Improvements in object exploration skills may facilitate the development of object segregation in early infancy. Journal of Cognition and Development, 1, 131-156.

Needham, A., Barrett, T., \& Peterman, K. (2002). A pick me up for infants' exploratory skills: Early simulated experiences reaching for objects using 'sticky' mittens enhances young infants' object exploration skills. Infant Behavior \& Development, 25, 279-295.

Newcombe, N. S., Sluzenski, J., \& Huttenlocher, J. (2005). Pre-existing knowledge versus on-line learning: What do young infants really know about spatial location? Psychological Science, 16, 222-227.

Piaget, J. (1954). The construction of reality in the child. New York: Basic Books.

Smith, L., Thelen, E., Titzer, R., \& McLin, D. (1999). Knowing in the context of acting: The task dynamics of the A-not-B error. Psychological Review, 106, 235-260.

Sommerville, J. A., Woodward, A. L., \& Needham, A. (2005). Action experience alters 3-month-old infants' perception of others' actions. Cognition, 96, B1-B11.

Spelke, E. S. (1994). Initial knowledge: Six suggestions. Cognition, 50, 431-445.

Spelke, E. S., Breinlinger, K., Macomber, J., \& Jacobson, K. (1992), Origins of knowledge. Psychological Review, 99, 605-632.

Thelen, E., Corbetta, D., Kamm, K., Spencer, J., Schneider, K., \& Zernicke, R. F. (1993). The transition to reaching: Mapping intention and intrinsic dynamics. Child Development, 64, 1058-1098.

Thelen, E., Schöner, G., Scheier, C., \& Smith, L. B. (2001). The dynamics of embodiment: A field theory of infant perseverative reaching. Behavioral and Brain Sciences, 21, 1-86.

Wang, S., \& Baillargeon, R. (2005). Inducing infants to detect a physical violation in a single trial. Psychological Science, 16, 542-549.

Wang, S., \& Baillargeon, R. (2006). Infants' physical knowledge affects their change detection. Developmental Science, 9, 173-181.

Wang, S., \& Baillargeon, R. (in press). Can infants be "taught" to attend to 
a new physical variable in an event category? The case of height in covering events. Cognitive Psychology.

Wang, S., Baillargeon, R., \& Paterson, S. (2005). Detecting continuity violations in infancy: A new account and new evidence from covering and tube events. Cognition, 95, 129-173.

Wilcox, T. (1999). Object individuation: Infants' use of shape, size, pattern, and color. Cognition, 72, 125-166.

Wilcox, T., \& Chapa, C. (2004). Priming infants to attend to color and pattern information in an individuation task. Cognition, 90, 265-302.

Wilcox, T., \& Woods, R. (in press). Experience primes infants to individuate objects: Illuminating learning mechanisms. In A. Woodward \& A.
Needham (Eds.), Learning and the infant mind. New York: Oxford University Press.

Willatts, P. (1997). Beyond the "couch potato" infant: How infants use their knowledge to regulate action, solve problems, and achieve goals. In G. Bremner, A. Slater, \& G. Butterworth (Eds.), Infant development: Recent advances (pp. 109-135). Hove, England: Psychology Press.

Received August 29, 2006

Revision received May 11, 2007

Accepted May 16, 2007

\section{Call for Papers:}

\section{Special Section on Three-Generation Research on Parenting and Its Consequences}

Developmental Psychology invites manuscripts for a special section on three-generation research on parenting and its consequences to be compiled by guest editors Rand Conger, Jay Belsky, and Deborah Capaldi working together with Associate Editor Richard Lerner.

The goal of the special section is to highlight recent high quality, prospective, longitudinal research on intergenerational continuities and discontinuities in parenting behavior and their consequences for child and adolescent development. Topics might include, but are not limited to, examination of the following:

- Mediating mechanisms that link quality of parenting in one generation to quality of parenting in the next,

- Social or personal events or conditions that either reduce or increase (i.e., moderate) the degree of intergenerational continuity in the quality of parenting behavior,

- Factors that disrupt intergenerational continuity in abusive parenting,

- The role of continuity in parenting as a nexus for similar developmental trajectories of children or adolescents in one generation and their children in the next generation, and

- Methodological issues related to the study of intergenerational continuity in parenting and its consequences.

Especially welcomed are papers that report the results of research on understudied populations such as ethnic minorities or rural as well as urban parents and children. The submission of recently completed doctoral dissertations is also encouraged.

The submission deadline is February 1, 2008. Initial inquiries regarding the special section may be sent to Rand Conger at rdconger@ucdavis.edu, Jay Belsky at j.belsky@bbk.ac.uk, or Deborah Capaldi at deborahc@oslc.org. Manuscripts must be submitted electronically through the Manuscript Submission Portal of Developmental Psychology at http://www.apa.org/journals/dev.html. Please be sure to specify in the cover letter that your submission is intended for the special section. For instructions to authors and other detailed submission information, see the journal website at http://www.apa.org/journals/dev.html. 